\title{
Safety and Technical Success of CT-Guided Bone Marrow Biopsy in Obese Patients
}

\author{
Barbara Manchec ${ }^{1}$ Joseph Limback ${ }^{1}$ Bo Liu ${ }^{2} \quad$ Julie W Pepe ${ }^{3}$ Jeremy Burt ${ }^{1} \quad$ Francisco Contreras $^{1}$ \\ Thomas J. Ward ${ }^{1, \odot}$
}

${ }^{1}$ Department of Radiology, Advent Health, Orlando, Florida, United States

2 Miami Cardiac and Vascular Institute, Miami, Florida, United States

${ }^{3}$ Center for Collaborative Research, Advent Health, Orlando, Florida, United States

Address for correspondence Thomas J. Ward, MD, Department of Radiology, Advent Health, 601 E Rollins St., Orlando, FL 32813, United States (e-mail: thomasjward@gmail.com).

J Clin Interv Radiol ISVIR 2020;4:16-19

\begin{abstract}
Purpose Obesity can make bone marrow biopsy using manual landmarks as guidance technically challenging. This retrospective review was performed to assess the safety and technical success of performing bone marrow biopsies with computed tomography (CT)-guidance in obese patients.

Materials and Methods This single-institution, retrospective study included 1,016 CT-guided bone marrow biopsies performed between 2009 and 2016. Thirty-four percent $(n=348)$ were performed in patients with a body mass index (BMI) of $30 \mathrm{~kg} / \mathrm{m}^{2}$ or greater, and $7 \%(n=75)$ were performed in patients with a BMI greater than $40 \mathrm{~kg} /$ $\mathrm{m}^{2}$. Demographic information, BMI, and complications were reviewed. The primary endpoint was technical success and procedurally related hemorrhagic complication. The electronic medical record was reviewed to identify procedural related hemorrhagic complications, Common Terminology Criteria for Adverse Events (CTCAE) Grade 3 or above. The complication rates in obese patients were compared with patients with a BMI less than $30 \mathrm{~kg} / \mathrm{m}^{2}$.

Results Biopsy was successfully performed in all patients. No biopsies resulted in a CTCAE Grade 3 or above complication. There was no difference in complication rate $(0 \%)$ based on BMI. For patients with a $\mathrm{BMI}<30 \mathrm{~kg} / \mathrm{m}^{2}, \mathrm{BMI} \geq 30 \mathrm{~kg} / \mathrm{m}^{2}$, and $\mathrm{BMI}>40 \mathrm{~kg} / \mathrm{m}^{2}$, complications rates were $0 \%$ (95\% confidence interval $[\mathrm{Cl}]: 0-0.4 \%$ ),

Keywords

- bone marrow examination

- image-guided biopsy

- obesity $0 \%$ (95\% Cl: 0-0.9\%), and 0\% (95\% Cl: 0-4\%), respectively.

Conclusions $\mathrm{CT}$-guided bone marrow biopsy in obese patients can be performed with a high rate of technical success and is safe. If patient body habitus limits the ability to palpate physical landmarks needed to perform bone marrow biopsy without image guidance, CT-guided bone marrow biopsy should be considered.
\end{abstract}

\section{Introduction}

Bone marrow biopsy and aspiration is a commonly performed procedure, used to aid in the diagnosis, monitoring, and staging of multiple diseases, primarily hematologic or metastatic in nature. The retrieved specimens provide vital information regarding the patient's disease, through the use of immunohistochemical stains, cytogenetic analysis, flow cytometry, and molecular assays. ${ }^{1,2}$

Overall, bone marrow biopsy is a safe procedure, with a complication rate of less than $0.1 \%^{3-5}$ The most common complication reported is hemorrhage. ${ }^{3,4,6}$ Obese patients tend to have higher levels of coagulation factors and lower levels of tissue plasminogen activator (t-PA) activity, ${ }^{7}$ and some
DOI https://doi.org/ 10.1055/s-0039-3401330 ISSN 2457-0214.
License terms

() (1) $\ominus \circledast$ 
studies have shown increased bleeding in patients undergoing percutaneous coronary intervention with a lower body mass index (BMI). ${ }^{8}$ This data suggests that obesity could potentially protect against bleeding; however, obesity is a risk factor for hemorrhage after bone marrow biopsy. $3,5,6$ Excess adipose tissue can make bedside bone marrow biopsies technically challenging due to the loss of physical landmarks used to guide biopsy. ${ }^{9,10}$

Performing a bedside bone marrow biopsy without palpable physical landmarks risks neurovascular injury if the needle is advanced into an adjacent tissue compartment other than the iliac bone. If the gluteal compartment is entered, there is risk of gluteal artery hemorrhage, pseudoaneurysm, or gluteal compartment syndrome., ${ }^{5,11}$ If the needle is advanced too deeply and penetrates the inner iliac cortex, it can result in iliac and/or pelvic vessel injury and lead to retroperitoneal hemorrhage., 511

Use of computed tomography (CT)-guidance has been proven to be safe and efficacious for liver and renal biopsies in obese patients, with the added benefit of more rapid identification of complications. ${ }^{11-13}$ This retrospective review was performed to test the hypothesis that performing bone marrow biopsies with CT guidance in obese patients is technically feasible and safe.

\section{Materials and Methods}

This institutional review board-approved study was designed as a retrospective cohort study with the primary endpoint being the occurrence of Common Terminology Criteria for Adverse Events (CTCAE) Grade 3 or above hemorrhagic complication. ${ }^{14}$ There was a waiver granted for informed consent, compliant with the Health Insurance Portability and Accountability Act. The authors have no conflicts of interest to report.

\section{Patient Selection}

A database of bone marrow biopsies performed within our institution between May 1, 2009, and May 1, 2016, was retrospectively collected with patients identified using Montage Search and Analytics software (Montage Healthcare Solutions). All patients who underwent CT-guided bone marrow biopsies were included. Patients who underwent bone marrow biopsy without CT-guidance were excluded along with all biopsies outside of the approved study time frame. Patients who did not have weight or height documented within one month of the biopsy were also excluded. A total of 1,023 bone marrow biopsies were performed using $\mathrm{CT}$ guidance during the study period; 7 were excluded because weight or height was not documented. The patients in this study were previously studied to assess the impact of platelet count on risk of hemorrhagic complication. ${ }^{15}$ Although the biopsies were performed in a hospital setting, the study population included both inpatients and outpatients.

Of the final population of 1,016 biopsies, mean age was 57 years (range 15-93 years), 492 patients were female (48\%), and 524 patients were male (52\%). Thirty-four percent
( $n=348)$ of bone marrow biopsies were performed on inpatients with a BMI of $30 \mathrm{~kg} / \mathrm{m}^{2}$ or greater.

\section{Biopsy Procedure}

Procedural consents were obtained prior to the start of each procedure. After positioning the patient in the prone position, sedation was administered by either the interventional radiologist or separate anesthesia staff. Although sedation information was not assessed in these patients, at the performing institution, sedation is typically performed with a combination of midazolam, fentanyl, and/or propofol for these procedures. A limited field of view low-dose CT scan of the pelvis was then obtained for procedural planning. For local anesthesia, $2 \%$ lidocaine was administered along the expected needle trajectory, to include the skin and periosteum of the posterior superior iliac crest. A Carefusion AVAmax 11-gauge coaxial biopsy needle system (BD-Carefusion) was advanced through the cortical bone where an aspirate and core biopsy was obtained ( $\boldsymbol{-}$ Fig. $\mathbf{1}$ ). The bone marrow aspiration was performed by attaching a syringe to the 11 -guage access cannula. Subsequently, a single core biopsy with a 14-guage biopsy needle was performed through the access cannula. All patients were instructed to lie flat on their back for 1 hour after the procedure and vital signs were monitored every 15 minutes during recovery. Nursing staff was instructed to inform the interventional radiologist if the patient experienced increased pain or bleeding at the biopsy site. After 1 hour in recovery, inpatients were transported to their hospital room and outpatients were allowed to go home (with a driver).

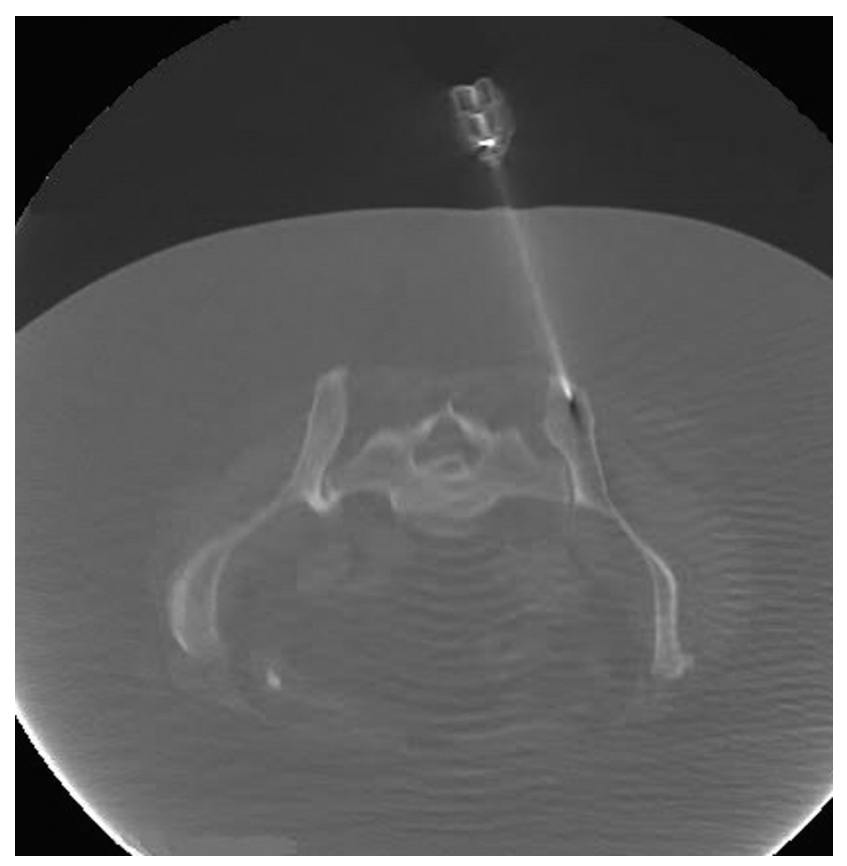

Fig. 1 Axial computed tomography (CT) image in bone window demonstrates a biopsy needle extending into the posterior right iliac bone, through the use of a lateral approach. Note the prominent subcutaneous tissue, which could potentially limit use of guidance using anatomic landmarks. 


\section{Assessment of Complications}

Each patient's medical record was reviewed, including the 48 hours following each biopsy to identify CTCAE Grade 3 or above complications. A Grade 3 arterial injury complication is defined as any injury that results in severe symptoms and requires repair or intervention. The electronic medical record was reviewed for all patients, with attention for any postprocedural imaging demonstrating a biopsy site hematoma, any hemoglobin drop greater than $2 \mathrm{~g} / \mathrm{dL}$ following the procedure, or any evidence of sustained hemodynamic instability requiring initiation of vasopressors. Subjective biopsy site pain/discomfort without corresponding vital sign instability or biopsy site bleeding/hematoma was not considered a significant complication.

\section{Statistical Analysis}

The hemorrhagic complication rates of the patients were calculated for patients with normal BMI, BMI of $30 \mathrm{~kg} / \mathrm{m}^{2}$ or greater, and BMI greater than $40 \mathrm{~kg} / \mathrm{m}^{2}$. The complication rates for obese patients (BMI $\geq 30 \mathrm{~kg} / \mathrm{m}^{2}$ and BMI $>40 \mathrm{~kg} / \mathrm{m}^{2}$ ) were compared with patients with BMI less than $30 \mathrm{~kg} / \mathrm{m}^{2}$. Two-tailed 95\% confidence intervals based on Poisson distribution for complication rate in obese patients were also calculated. Continuous data are presented as mean and standard deviation and compared using the unpaired $t$-test. Categorical data are presented as percentages and counts and compared using the chi-square test. SPSS v.22.0.0 (SPSS Inc.) was used for statistical analysis.

\section{Results}

Of the 1,016 patients in the study population, 348 were had a BMI $\geq 30 \mathrm{~kg} / \mathrm{m}^{2}$ and 75 had a BMI $>40 \mathrm{~kg} / \mathrm{m}^{2}$. The highest BMI included in our study population was $66.7 \mathrm{~kg} / \mathrm{m}^{2}$. Thirty-seven percent of the female population was obese, with $8 \%$ having a BMI $>40 \mathrm{~kg} / \mathrm{m}^{2}$. Thirty-one percent of the male population was classified as obese, with $6 \%$ having a BMI $>40 \mathrm{~kg} / \mathrm{m}^{2}$. This was not significantly different between groups $(p=0.12)$. Demographic information is presented in - Table $\mathbf{1}$.

Technical success was achieved in all patients. Out of 1,016 biopsies, 0 resulted in a complication. No interventions or transfusions were needed for procedure-related bleeding. There were no instances of clinically symptomatic bleeding and no imaging was performed for suspicion of bleeding. There was no difference in rate of hemorrhagic complications $(0 \%)$ based on BMI $(p=1.0)$. For patients with BMI less than $30 \mathrm{~kg} / \mathrm{m}^{2}$, the rate for hemorrhagic complications was $0 \%$ (95\% confidence interval $[\mathrm{Cl}]: 0-0.4 \%$ ). For patients with a BMI of $30 \mathrm{~kg} / \mathrm{m}^{2}$ or greater, the rate for hemorrhagic complications was $0 \%$ (95\% CI: $0-0.9 \%$ ). For patients with a BMI greater than $40 \mathrm{~kg} / \mathrm{m}^{2}$, the rate for hemorrhagic complications was $0 \%(95 \% \mathrm{CI}$ : $0-4 \%)$.

\section{Discussion}

Bone marrow biopsies are indicated for the diagnostic work-up and monitoring of several disease pathologies, including malignancy, hematologic abnormalities, and infection. Most frequently the bone marrow aspiration and core biopsy are performed on the posterior superior iliac crest. ${ }^{16}$ This is in part due to the accessibility and ease of identification of the anatomic landmarks, lack of large overlying vessels or nerves, as well as the characteristically delayed loss of cellularity of the axial skeleton. However, in obese patients, identification of the anatomic landmarks by physical exam can be unreliable, and in this setting, imaging guidance via the use of $\mathrm{CT}$ is helpful. ${ }^{17}$ CT-guided bone marrow biopsy was technically successful in all of the obese patients, but, to the authors knowledge, there is no reported incidence of the technical success of blinded bone marrow biopsies in this patient population for comparison.

Although bone marrow aspiration and core biopsy is a low-risk procedure with rare complications, it is not without risk., ${ }^{3,5}$ One study of blind bone marrow aspiration for reconstructive orthopedic surgery reported a major complication rate of $0.6 \%$ and a minor complication rate of $2 \%{ }^{18}$ Major complications included hematoma requiring transfusion and gait disturbance for 2 months. ${ }^{18}$ This study required large bone marrow aspiration volumes, so the orthopedic surgeons made multiple passes into the bone through the same skin incision which may have resulted in a higher incidence of complication compared with diagnostic (lowvolume) bone marrow aspiration. ${ }^{18}$ Another study reported hemorrhage in only $0.07 \%$ of patients; however, it was "lifethreatening or contributed to death" in 3 of the 10 patients who suffered this complication. ${ }^{4}$ Reported risk factors for hemorrhagic complication after bone marrow biopsy include a diagnosis of a myeloproliferative disorder, aspirin therapy, warfarin therapy, disseminated intravascular coagulation (DIC), thrombocytopenia ranging from $25,000-68,000 / \mu \mathrm{L}$, and obesity., ${ }^{3,5}$ To the authors' knowledge, no prior study evaluates complication rate of bone marrow biopsy or aspiration in the obese population. While some make the argument that a highly experienced operator can successfully perform bone marrow biopsies without anatomic landmarks, others advocate for the use of CT guidance to safely

Table 1 Patient demographic information

\begin{tabular}{|c|c|c|c|c|c|}
\hline & \multicolumn{2}{|c|}{ Men $(n=524)$} & \multicolumn{2}{|c|}{ Women $(n=492)$} & \multirow[t]{2}{*}{$p$-value } \\
\hline & $n$ & $\%$ & $n$ & $\%$ & \\
\hline $\mathrm{BMI}<30 \mathrm{~kg} / \mathrm{m}^{2}$ & 360 & $69 \%$ & 308 & $63 \%$ & \multirow[t]{3}{*}{0.12} \\
\hline BMI: $30-40 \mathrm{~kg} / \mathrm{m}^{2}$ & 130 & $25 \%$ & 143 & $29 \%$ & \\
\hline $\mathrm{BMI}>40 \mathrm{~kg} / \mathrm{m}^{2}$ & 34 & $6 \%$ & 41 & $8 \%$ & \\
\hline Age (y) & 58 & 15.1 & 57.4 & 15.2 & 0.55 \\
\hline
\end{tabular}


perform the procedure. Devaliaf and Tudor were some of the first to advocate the use of $\mathrm{CT}$ guidance for bone marrow biopsy of hematologic disorders, rather than just for osseous lesions. ${ }^{9}$ In response, Ghosh stated that CT-guided biopsy is rarely needed, unless unguided biopsy fails and an anterior approach is to be attempted. ${ }^{9,19}$

Worldwide obesity has tripled since $1975,{ }^{20}$ and will likely lead to increased obesity-related morbidity in medicine. While bone marrow biopsy complications may not be directly associated with obesity, the inciting factor is often an inability to determine landmarks and/or needle position. ${ }^{21-26}$ Performing bone marrow biopsy under CT guidance eliminates the need for bony landmarks and should be considered as a safe alternative in these patients.

This study is limited by the retrospective nature of the study, which lends itself to selection bias. Patients in this cohort are, by nature, more likely to be sicker than those in whom the referring physician felt comfortable performing the biopsy at bedside or in clinic. However, this would further support the safety of CT-guided bone marrow biopsies in the obese population. Furthermore, this study was not able to assess if the risk hemorrhagic complication in obese patients is reduced by using CT guidance because it did not include obese patients who underwent blind bone marrow biopsy. In addition, restricting the postprocedure observation period to 48 hours could have resulted in potentially missing a delayed complication.

This retrospective study demonstrated that CT-guided bone marrow biopsy in obese patients is performed with high probability of technical success and is safe. In obese patients who lack the physical landmarks used to guide bedside bone marrow biopsy, CT guidance should be considered.

\section{Financial Disclosures}

None.

\section{Conflicts of Interest}

The authors have no relevant conflicts of interest.

\section{Acknowledgment}

The authors would like to acknowledge research coordinator Carole Coyne for her assistance in this project. The authors would also like to acknowledge Melissa Kendall, Michael Valente, Jamil Armaly, Vincent Grekoski, and Alex Pinizzotto for their assistance with the data collection.

\section{References}

1 Hyun BH, Stevenson AJ, Hanau CA. Fundamentals of bone marrow examination. Hematol Oncol Clin North Am 1994;8(4):651-663

2 Riley RS, Williams D, Ross M, et al. Bone marrow aspirate and biopsy: a pathologist's perspective. II. interpretation of the bone marrow aspirate and biopsy. J Clin Lab Anal 2009;23(5):259-307

3 Bain BJ. Bone marrow biopsy morbidity: review of 200. J Clin Pathol 2005;58(4):406-408

4 Bain BJ. Bone marrow biopsy morbidity and mortality: 2002 data. Clin Lab Haematol 2004;26(5):315-318

5 Bain BJ. Morbidity associated with bone marrow aspiration and trephine biopsy-a review of UK data for 2004. Haematologica 2006;91(9):1293-1294
6 Bain BJ. Bone marrow biopsy morbidity and mortality. $\mathrm{Br}$ J Haematol 2003;121(6):949-951

7 Braekkan SK, van der Graaf Y, Visseren FL, Algra A. Obesity and risk of bleeding: the SMART study. J Thromb Haemost 2016;14(1):65-72

8 Delhaye C, Wakabayashi K, Maluenda G, et al. Body mass index and bleeding complications after percutaneous coronary intervention: does bivalirudin make a difference? Am Heart J 2010;159(6):1139-1146

9 Devaliaf V, Tudor G. Bone marrow examination in obese patients. Br J Haematol 2004;125(4):538-539

10 Friedlis MF, Centeno CJ. Performing a better bone marrow aspiration. Phys Med Rehabil Clin N Am 2016;27(4):919-939

11 Konda B, Pathak S, Edwin I, et al. Safe and successful bone marrow biopsy: an anatomical and CT-based cadaver study. Am J Hematol 2014;89(10):943-946

12 Rockey DC, Caldwell SH, Goodman ZD, Nelson RC, Smith AD; American Association for the Study of Liver Diseases. Liver biopsy. Hepatology 2009;49(3):1017-1044

13 Mukhtar KN, Mahmood SN, Umair SF. CT guided percutaneous renal biopsy versus ultrasound guided for obtaining adequate tissue. J Pak Med Assoc 2012;62(9):880-882

14 U. S. Department of Health and Human Services, National Institute of Mental Health, National Cancer Institute. Common Terminology Criteria for Adverse Events (NIH Publication No. 09-5410). Bethesda, MD: U.S. Government Printing Office, 2015

15 Liu B, Limback J, Kendall M, et al. Safety of CT-guided bone marrow biopsy in thrombocytopenic patients: a retrospective review. J Vasc Interv Radiol 2017;28(12):1727-1731

16 Riley RS, Hogan TF, Pavot DR, et al. A pathologist's perspective on bone marrow aspiration and biopsy: I. Performing a bone marrow examination. J Clin Lab Anal 2004;18(2):70-90

17 Badiola CM, Scappaticci F, Brahaj D. CT guided bone marrow aspiration and core biopsy. Open Journal of Radiology 2012;2(2):55-56

18 Hernigou P, Desroches A, Queinnec S, et al. Morbidity of graft harvesting versus bone marrow aspiration in cell regenerative therapy. Int Orthop 2014;38(9):1855-1860

19 Ghosh K. Bone marrow examination in obese patients: CAT or not to CAT! Br J Haematol 2004;127(2):230-231, authorreply 231

20 World Health Organization. Obesity and overweight fact sheet. Available at: https://www.who.int/news-room/ fact-sheets/detail/obesity-and-overweight. Accessed March 13, 2020

21 Griselli F, Calvagna C, Sgorlon G, et al. Management of an iatrogenic pseudoaneurysm of the superior gluteal artery by percutaneous ultrasound-guided thrombin injection: a case report. Ann Vasc Surg 2017;38:317.e9-317.e11

22 Arellano-Rodrigo E, Real MI, Muntañola A, et al. Successful treatment by selective arterial embolization of severe retroperitoneal hemorrhage secondary to bone marrow biopsy in post-polycythemic myelofibrosis. Ann Hematol 2004;83(1):67-70

23 Yap WT, Jeffrey RB. Sonographic diagnosis of a superior gluteal artery arteriovenous fistula and pseudoaneurysm after bone marrow biopsy. J Ultrasound Med 2016;35(5):1104-1106

24 Caldwell IR, Buckley BT, Rajagopal R, Doocey R, Pemberton L. Traumatic superior gluteal artery pseudoaneurysm following a bone marrow biopsy. Intern Med J 2016;46(3):374-375

25 Ge PS, Ng G, Ishaque BM, Gelabert H, de Virgilio C. Iatrogenic pseudoaneurysm of the superior gluteal artery presenting as pelvic mass with foot drop and sciatica: case report and review of literature. Vasc Endovascular Surg 2010;44(1):64-68

26 Al Zahrani Y, Peck D. Median sacral artery injury following a bone marrow biopsy successfully treated with selective trans-arterial embolization: a case report. J Med Case Reports 2016;10:42 